\title{
Production planning of a hybrid manufacturing/remanufacturing system under uncertainty within a closed-loop supply chain
}

\author{
Jean-Pierre Kenné ${ }^{1}$, Pierre Dejax ${ }^{2}$ and Ali Gharbi ${ }^{3}$ \\ ${ }^{1}$ Mechanical Engineering Department, Laboratory of Integrated Production Technologies, University of Quebec, \\ École de technologie supérieure, 1100, Notre Dame Street West, Montreal (Quebec), Canada, H3C 1K3 \\ ${ }^{2}$ Department of Automatic Control and Industrial Engineering, Logistics and Production Systems Group, Ecole des \\ Mines de Nantes, IRCCyN, BP 20722 - 44307 Nantes Cedex 3 - France \\ ${ }^{3}$ Automated Production Engineering Department, Production Systems Design and Control Laboratory, University \\ of Quebec, École de technologie supérieure, 1100, Notre Dame Street West, Montreal (Quebec), Canada, H3C 1K3
}

\begin{abstract}
This paper deals with the production planning and control of a single product involving combined manufacturing and remanufacturing operations within a closed-loop reverse logistics network with machines subject to random failures and repairs. While consumers traditionally dispose of products at the end of their life cycle, recovery of the used products may be economically more attractive than disposal and remanufacturing of the products also pursue sustainable development goals. Three types of inventories are investigated in this paper. The manufactured and remanufactured items are stored in the first and second inventories. The returned products are collected in the third inventory and then remanufactured or disposed of. The objective of this study is to propose a manufacturing/remanufacturing policy that would minimise the sum of the holding and backlog costs for manufacturing and remanufacturing products. The decision variables are the production rates of the manufacturing and the remanufacturing machines. The Optimality conditions are developed using the optimal control theory based on stochastic dynamic programming. A computational algorithm, based on numerical methods, is used for solving the optimal control problem. Finally, a numerical example and a sensitivity analysis are presented to illustrate the usefulness of the proposed approach. The structure of the optimal control policy is discussed depending on the value of costs and parameters and extensions to more complex reverse logistics networks are discussed.
\end{abstract}

Key words: Reverse logistics, closed-loop supply chains, manufacturing/remanufacturing, optimal control, production Planning, stochastic dynamic programming, Numerical methods.

\section{Introduction}

The management of return flows induced by the various forms of reuse, or recovery of products and materials in industrial production processes has received growing attention throughout the last two decades among practitioners as well as scientists. This is due to the constant search for increased productivity, a better service to clients, as well as environmental 
concerns and the goals of sustainable development in general. Work in this area may be found as early as the 1900's. As an example, Amezquita and Bras (1996) analyzes the remanufacturing of an automobile clutch and Lund (1996) edited a comprehensive report on the remanufacturing industry. According to the American Reverse Logistics Executive Council, "Reverse logistics can be viewed as the process of planning, implementing and controlling the efficient, cost effective flow of raw materials, in-process inventory, finished goods and related information, from the point of consumption back to the point of origin, for the purpose of recapturing their value or proper disposal” (Rogers and Tibben-Lembke, 1998).

As mentioned in Fleischmann et al. (1997), reverse logistics encompasses the logistic activities all the way from used products no longer required by the user to products again usable in a market. There is a major distinction between material recovery (recycling) and added value recovery (repair, remanufacturing). They describe the general framework of Reverse distribution, composed of the "Forward channel" (going from the suppliers and through the producers and distributors to the consumers, and of the "Reverse channel", going back from the consumers through collectors and recyclers, to the suppliers or producers. In all cases, the reuse opportunities give rise to a new material flow from the user back to the sphere of producers. The management of this material backward flow opposite to the conventional forward supply chain flow is the concern of the recently emerged field of «reverse logistics».

Reverse logistics systems have been classified into various categories depending on the characteristics that are emphasized. Thus several classifications may be found in the literature: Seaver (1994) focuses on design considerations for the different types of recovery operations based upon the Xerox Corporation experience; Fleischmann et al. (1997) propose a comprehensive review of quantitative approaches and distinguish the types of returned items; Rogers and Tibben-Lembke (1998) analyze trends and practices; Thierry et al. (1995) analyze the main options for recovery. Theses authors distinguish two categories or reverse logistic systems and four types or return items or services. The two categories of reverse logistic systems are open and closed-loop systems, depending on whether the return operations are integrated or not with the initial operation. The four categories of return items or services are the following: reusable items (such as returned products or pallets), repair services (where the products are sent 
back to the consumer after repair), remanufacturing, an industrial process in which used, end of life products are restored to like-new conditions and put back into the distribution system like the "new products" and the recycling of raw materials and wastes.

Many case studies and papers proposing models have been published in the area of reverse logistics as well as several reviews. See De Brito et al. (2003) for a review of case studies; Dekker et al. (2004) for a review of quantitative models for closed-loop supply chains; Geyer and Jackson (2004) propose a framework to help identify and assess supply loop constraints and strategies and they apply it to the recycling and reuse of structural steel Sections in the construction sector; and Bostel et al. (2005) for a review of optimization models in terms of strategic, tactical and operational planning. Special issues of journals have been devoted to the area of reverse, or closed-loop logistics: Verter and Boyaci (2006) edited a special issue journal on optimization models for reverse logistics. Guide and Van Wassenhove (2006, Part 1 and Part 2) edited a two parts feature issue journal on Closed-Loop Supply Chains.

As can be seen from the numerous published literatures on reverse logistics, many industrial cases have been reported and many scientific planning or optimization models have been proposed. These cases and models differ by numerous characteristics. One of the the most complex situation is found in remanufacturing activities. Traditional areas for remanufacturing are the automotive or aeronautic sectors (machinery and mechanical assemblies such as aircraft engines and machine tools) as well as the remanufacturing of toner cartridges (see the report by Lund (1996) about the remanufacturing industry. An example is Hewlett-Packard, which collects empty laser-printer cartridges from customers for using again (Jorjani et al. (2004)). Other examples are described in the next Section.

Individual repair requirements for every product returned, and coordination of several interdependent activities makes production planning a highly sophisticated task in this environment. In contrast with traditional manufacturing systems (forward direction), no welldetermined sequence of production policies exist in remanufacturing (backward or reverse direction). This is illustrated by Sundin and Bras (2005) who describes a model of 
remanufacturing steps not following a specific order. In many cases, the original manufacturer is also in charge of collecting, refurbishing, and remanufacturing the used products.

The production planning in a hybrid context, involving manufacturing and remanufacturing facility, referred to as forward-reverse logistics in a closed-loop network, is very complex especially in the presence of uncertainties and under the consideration of the overall system's dynamics. Much of the work in the area of remanufacturing is devoted to the strategic design of the closed-loop system, or to the tactical or operational planning of production and management of inventories, considering discrete periods of time. See the next Section for a more comprehensive review of literature related to the remanufacturing activities.

In this paper we address the area of an integrated combined manufacturing / remanufacturing within a closed-loop supply chain subject to uncertainties. We study the production planning of a hybrid manufacturing/remanufacturing system in a dynamic continuous time stochastic context. Uncertainties are due to machine failures and continuous time modeling seems to us a better framework to consider stochastic aspects. We found no such approach in the published literature on remanufacturing. We develop a generic stochastic optimization model of the considered problem with two decision variables (production rates of manufacturing and remanufacturing machines) and two state variables (stock levels of manufactured and remanufactured products). Our goal is to characterize optimal policies for the production rates of the new products as well as the remanufactured products, depending on the values of the model parameters and costs.

Our modeling approach could possibly be applied to many industrial cases such as those mentioned in this Section or the next where machines can be subject to failures and their production rates can be continuously controlled. We feel the assumptions made can be acceptable, at least approximately, in many cases, but this should be verified as the first step of an industrial application. It is assumed in particular that the remanufactured products can be considered meeting the same quality level as the new products so that both type of products can be distributed like new. We also assume that the demand for new products is deterministic and known in advance and the proportion of returned products to be possibly remanufactured is a known proportion of demand. A typical example might be the remanufacturing of copier cartridges, or aeronautical parts. 
The rest of the paper is organised as follows. In Section 2, the literature review is presented. The model notations, the assumptions and the control problem are presented in Section 3. A numerical example and a sensitivity analysis (carried out to analyse the effect of the used products return ratio and the backlog costs), are given in Sections 4 and 5, respectively. Discussions and the direction for future works are presented in Section 6. The paper concludes with a short summary in Section 7.

\section{Literature review}

In this Section, we focus on cases and models related to remanufacturing activities. A number of practical cases have been reported in various contexts of application. Many works are devoted to the design of the network system or to production or inventory planning through discrete optimization models.

De Brito et al (2003) discuss network structures and report cases pertaining to the design of remanufacturing networks by the original equipment manufacturers or independent manufacturers, the location of remanufacturing facilities for copiers, especially Canon copiers and other equipments and the location of IBM facilities for remanufacturing in Europe. They also present case studies on inventory management for remanufacturing networks of engine and automotive parts for Volkswagen and on Air Force depot buffers for disassembly, remanufacturing and reassembly. Finally, they present case studies on the planning and control of reverse logistics activities, and in particular inventory management cases for remanufacturing at a Pratt \& Whitney aircraft facility, yielding decisions of lot sizing and scheduling.

As mentioned above their survey on design, planning and optimization of reverse logistic networks, Bostel et al (2005) propose a classification of problems and models according to the hierarchical planning horizon. Strategic planning models are devoted to network design problems, while tactical and operational models to a number of short terms issues. In this context they discuss a number of inventory management models with reverse flows, including periodic and continuous review deterministic and stochastic inventory models. They also present production planning models, including for disassembly levelling and planning and production 
planning and scheduling models involving return products. These models may include remanufacturing activities.

The special issue published by Verter and Boyaci (2006) contains three papers optimization models for facility location and capacity planning for remanufacturing and a paper on assessing the benefits of remanufacturing options.

In the introduction to their Feature issues, Guide and Van Vassenhove (2006) discuss assumptions of models for reverse supply chain activities, and in particular for remanufacturing operational issues and remanufactured product market development. Several papers deal with optimal policies for remanufacturing activities, pertaining to acquisition, pricing, order quantities, lot sizing for products over a finite life cycle.

In recent years there has been considerable interest in inventory control for joint manufacturing and remanufacturing systems in forward-reverse logistics networks. A forwardreverse logistic network establishes a relationship between the market that releases used products and the market for new products as mentioned by El-Sayed et al. (2008). When the two markets coincide, then it is called a closed-network, otherwise it is called an open loop network (Salema et al. (2007)). In Ostlin et al. (2008), seven different types of closed-loop relationships for gathering cores for remanufacturing have been identified (ownership-based, service-contract, direct- order, deposit-based, credit-based, buy-back and voluntary-based relationships). Several disadvantages and advantages are described in Ostlin et al. (2008) according to such types of relationships. By exploring these relationships, a better understanding can be gained about the management of the closed-loop supply-chain and remanufacturing. In a close loop network, the kind of planning problems arising and the adequacy of traditional production planning methods depend, to a large extent, on the specific form of reuse considered. Material recycling surely does involve new production processes. Returned parts and products may have to be transformed back into raw material by means of melting, grinding, etc. However, the difficulty lies in the technical conversion to usable raw materials rather than in managerial planning and control of these activities. From a production management point of view, these activities are no different from other production processes. Consequently, conventional production planning methods should 
suffice to plan and control recycling operations for products that can be sent back to the market, in order to recapture the maximum value. The order of remanufacturing steps are very much dependent on the type of product being remanufactured, where it is collected from, its relationship to the user and manufacturer, volumes etc. The situation may become more complex if disassembly is required prior to the actual recycling process.

Dobos (2003) found optimal inventory policies in a reverse logistics system with special structure while assuming that the demand is a known function in a given planning horizon and the return rate of used items is a given function. The demand is satisfied from the first store, where the manufactured and remanufactured items are stored. The returned products are collected in the second store and then remanufactured or disposed of. Dobos (2003) minimized the sum of the holding costs in the stores and costs of the manufacturing, remanufacturing and disposal. The necessary and sufficient conditions for optimality were derived from the application of the maximum principle of Pontryagin (Seierstad and Sydsaeter (1987)). Their results are limited to deterministic demand and return process with no consideration on the dynamics of production facilities. Taking a closer look at the dynamic characteristic of the production planning problems, one can notice that the stochastic optimal control theory, such as in Akella and Kumar (1986), Dehayem et al. (2009), Hajji et al, (2009) and references therein, is not yet used in reverse logistics.

Kibum et al. (2006) discussed the remanufacturing process of reusable parts in reverse logistics, where the manufacturing has two alternatives for supplying parts: either ordering the required parts to external suppliers, or overhauling returned products and bringing them back to «as new» condition. They proposed a general framework for the considered remanufacturing environment and a mathematical model to maximize the total cost savings by optimally deciding (i) the quantity of parts to be processed at each remanufacturing facility, (ii) the number of purchased parts from subcontractor. The decision is optimally made using a mixed-integer programming model. The study presented in Chung et al. (2008) analysed a close-loop supply chain inventory system by examining used products returned to a reconditioning facility where they are stored, remanufactured, and then shipped back to retailers for retail sale. The findings of 
the study presented in Chung et al. (2008) demonstrate that the proposed integrated centralized decision-making approach can substantially improve efficiency.

The majority of the previous models are based on mathematical / linear programming. An example of such models can be found in El-Sayed et al. (2008) where a multi period multi echelon forward-reverse logistics network model is developed. The control of the manufacturing and remanufacturing production facilities, based on their dynamics is very limited in the literature. Kiesmuller and Scherer (2003) considered a system where remanufacturing processes are integrated into a single production environment. In this type of hybrid environment, new and reused products are processed separately. This control approach of hybrid production/remanufacturing systems leads to the definition of two different inventory positions or levels to control and synchronize each of the subsystems. The repair/remanufacturing system studied by Pellerin et al. (2009) differs from this environment as it responds to both remanufacturing orders and unplanned repair demands within the same execution system. In addition, there is a need to consider multiple remanufacturing rates for the current case. This additional complexity calls for a different control approach. Gharbi et al. (2008) treated such a problem by proposing a control policy for repair and remanufacturing system with limited capacity and solved the problem using a simulation approach. The stochastic model presented in Pellerin et al. (2009) and Gharbi et al. (2008) is based on a remanufacturing problem without any consideration on manufacturing planning problems.

Attention in the production planning problem in manufacturing systems subject to failures and repairs started growing with the pioneering work of Rishel (1975); it has since been followed by extensions, as in Akella and Kumar (1986), Kenné et al. (2003), and Dong-Ping (2009). Those extensions are based on continuous time stochastic models and the dynamic programming approach. The control policies are obtained either analytically (one machine, one product) or numerically for multiple machines or multiple products. We didn't found available results in hybrid manufacturing/remanufacturing with continuous control models in a stochastic context.

As mentioned in the introduction, a stochastic dynamic model is developed in this paper to optimize the performance of given forward-reverse logistics network. The considered reverse 
logistics network establishes a relationship between the market that releases used products and the market for "new" products. Very few optimization models for the control of supply chains with reverse flows are available in literature under uncertainty (without any simplified assumptions on the existence of stochastic processes). Therefore, in view of previous researches on the various specific areas of remanufacturing, our research focuses on developing a new generic model based on stochastic optimal control theory under uncertainties due to the dynamics of the production facilities. The proposed approach for the control of a stochastic hybrid manufacturing/remanufacturing system differs from existing approaches because it integrates the manufacturing/remanufacturing system's dynamics. The practical implication of the proposed model is examined through a numerical example and experimental analysis.

\section{Proposed control model}

This Section presents the notations and assumptions used throughout this article, and the optimal control problem statement.

\subsection{Notations}

$\begin{array}{ll}x_{1}(t) & \text { stock level of manufactured products } \\ x_{2}(t) & \text { stock level of remanufactured products } \\ x_{3}(t) & \text { stock level of the returned products } \\ \xi(t) & \text { stochastic process of the hybrid system } \\ \xi_{1}(t) & \text { stochastic process of the manufacturing machine } \\ \xi_{2}(t) & \text { stochastic process of the remanufacturing machine } \\ d_{c} & \text { demand rate of customers } \\ d_{r} & \text { remanufacturing demand rate } \\ d_{m} & \text { manufacturing demand rate } \\ d_{n s p} & \text { remanufacturing supplier rate } \\ d_{p} & \text { disposal rate } \\ d_{c r} & \text { product return rate from the market } \\ c_{r}^{1} & \text { repair cost for the manufacturing machine } \\ c_{r}^{2} & \text { repair cost for the remanufacturing machine } \\ c_{1}^{+} & \text {inventory holding cost for manufactured products } \\ c_{2}^{+} & \text {inventory holding cost for remanufactured products } \\ c_{1}^{-} & \text {backlog cost for manufactured products }\end{array}$




$\begin{array}{ll}c_{2}^{-} & \text {backlog cost for remanufactured products } \\ C_{\text {disposal }} & \text { disposal cost } \\ q_{\alpha \beta} & \text { transition rate from mode } \alpha \text { to } \beta \text { of the process } \xi(t) \text { with } \alpha, \beta \in\{1,2,3,4\} \\ q_{i j}^{k} & \text { transition rate from mode } i \text { to } j \text { of the process } \xi_{k}(t) \text { with } i, j \in\{1,0\} \text { and } k=1,0 \\ Q & \text { transition rate matrix } \\ \eta & \text { vector of limiting probabilities } \\ g(\cdot) & \text { instantaneous cost function } \\ J(\cdot) & \text { total cost } \\ v(\cdot) & \text { value function } \\ \rho & \text { discount rate } \\ u_{1}(t) & \text { production rate of the manufacturing machine } \\ u_{2}(t) & \text { production rate of the remanufacturing machine } \\ u_{\text {max }}^{1} & \text { maximal production rate of the manufacturing system } \\ u_{\max }^{2} & \text { maximal production rate of the remanufacturing system }\end{array}$

\subsection{Context and Assumptions}

The following summarizes the general context and main assumptions considered in this paper.

1. The model is a time continuous (not multi-period as usually assumed in the literature).

2. Customers' locations are known and fixed

3. The returned quantities are known functions of the initial customer demand.

4. The customer demand is known and subject to a constant rate over time.

5. The quality of remanufactured products is not different from manufactured products.

6. The potential locations of suppliers, facilities, distributors, etc. are known.

7. Material, manufacturing, non-utilized capacity, shortage, transportation, holding, recycling, remanufacturing, and disposal costs are known for each location.

8. The maximal production rates of each machine are known.

9. The shortage cost depends on the shortage quantity and time (average value (\$/product/unit of time)).

10. The holding cost depends on the mean inventory level (average value (\$/product/unit of time)).

11. The manufacturing and remanufacturing systems are unreliable product units subject to breakdown and working in a parallel structure. 
Assumption 1 is an original characteristic of our approach, due to the consideration of machine breakdowns with the stochastic control technique. Other works consider discrete periods of time. Assumptions 2 and 6 are classical assumptions in supply chain networks models. Assumption 3 is often made in these types of models: the rate of returned is a fixed, known proportion of the initial demand. See the list of assumptions of models made for reverse supply chain activity in the Introdution to the feature issue by Guide and Van Wassenhove (2006 part 1, Table 1): either constant return rates or normally distributed return rates are proposed. This latter would assumption would be the subject of further research. Assumption 4 is also common to deterministic demand distribution models. Assumption 5 is commonly made in remanufacturing models, under possible quality control or inspection conditions before the decision of remanufacturing is made. Assumption 7 about known unit cost is classical. Assumption 8 is common in production planning. Assumptions 9 and 10 are common in inventory management. Assumption 11 is the major motivation of our work. It is a classical assumption in production planning, but innovative in the remanufacturing area.

\subsection{Problem statement}

The considered hybrid manufacturing/remanufacturing system consists of two machines which are subject to random breakdowns and repairs denoted $M_{1}$ and $M_{2}$ for manufacturing and remanufacturing, respectively. We consider a one product recovery system where demands can be fulfilled from an inventory for serviceable items. This inventory can be replenished by production or by remanufacturing used and returned items. Another inventory is available for the stock keeping of the returned items ahead of the remanufacturing process. Thus, returned items can be remanufactured, disposed of, or be hold on stock for later remanufacturing. The situation is illustrated in Figure 1.

The system behaviour is described by a hybrid state comprising both a continuous component (stocks of products) and a discrete component (modes of the machines). The continuous component consists of continuous variables $x_{1}(t), x_{2}(t)$ and $x_{3}(t)$ corresponding to the stock level of manufactured products, remanufactured products and returned items.

These variables are described by three differential equations based on the dynamics of the involved three stock levels illustrated in Figure 1. 


$$
\begin{array}{ll}
\frac{d x_{1}(t)}{d t}=u_{1}(t)-d_{m} & x_{1}(0)=x_{1} \\
\frac{d x_{2}(t)}{d t}=u_{2}(t)-d_{r} & x_{2}(0)=x_{2} \\
\frac{d x_{3}(t)}{d t}=d_{c r}-d_{n s p}-d_{p} & x_{3}(0)=x_{3}
\end{array}
$$

The serviceable inventories $x_{1}(t)$ and $x_{2}(t)$ are replenished by manufactured and remanufacturing items, respectively, with $d_{c}=d_{m}+d_{r}$. We assumed that the product return rate from the market and the disposal rate are such that the remanufacturing machine $M_{2}$ is never starved. Thus, the decision variables are $u_{1}(t)$ and $u_{2}(t)$; and the state variable are $x_{1}(t)$ and $x_{2}(t)$ for given $d_{m}, d_{r}, d_{c}, d_{c r}, d_{p}$ and $d_{n s p}$. To achieve its main production goal, while meeting part demands from manufacturing plants, the company should determine how many returned products should be thrown into the remanufacturing process to be remanufactured as new ones.

The objective of the hybrid manufacturing/remanufacturing system is thus to provide a given portion of the overall production from new spare parts (returned products). For example, $d_{c r}$ could be $40 \%$ of $d_{c}$ with $d_{r}<d_{c r}$ (e.g., the value of $d_{r}$ depends on the objective of the remanufacturing activities). The average supply rate of the remanufacturing machine is equivalent to its production rate given that there is no store available on it. For example, if the remanufacturing is producing at its maximal rate $u_{\max }^{2}$, then the disposal rate is set to $d_{r c}-u_{\max }^{2}$ if the stock level of returned products is equal to a target value (fixed in this paper by a disposal policy not studied herein), to avoid any starvation of the remanufacturing machine.

The state of a machine can be classified as operational, denoted by 1, and under repair, denoted 0 . Let's say $\zeta_{i}(t), i=1,2$, denotes the state of the machine $M_{i}$ with value in $B_{i}=\{1,0\}$. Let us also define $q_{10}^{1}$ and $q_{10}^{2}$ as failure rates of $M_{1}$ and $M_{2}, q_{01}^{1}$ and $q_{01}^{2}$ as repair rates of $M_{1}$ and $M_{2}$. The dynamics of the hybrid system is described by a continuous time Markov process $\zeta(t)=\zeta_{1}(t) \times \zeta_{2}(t) \quad$ with $\quad$ values $\quad$ in $B=B_{1} \times B_{2}=\{(1,1),(1,0),(0,1),(0,0)\} \equiv\{1,2,3,4\} . \quad$ The transition rates from state $\alpha_{1}$ to state $\alpha_{2}$ are denoted $q_{\alpha_{1} \alpha_{2}}\left(\right.$ with $\left.\alpha_{1}, \alpha_{2} \in\{1,2,3,4\}\right)$ and 
determined from the failure and repair rates of $M_{1}$ and $M_{2}$ as in Table 1 . The transition diagram, describing the dynamics of the considered manufacturing/remanufacturing system is presented in Figure 2.

For the considered hybrid system, the corresponding $4 \times 4$ transition matrix $Q$ is one of an ergodic process. Hence, $\zeta(t)$ is described by the matrix $Q=\left\lfloor q_{\alpha \beta}\right\rfloor$ where $q_{\alpha \beta}$ verify the following conditions:

$$
\begin{gathered}
q_{\alpha \beta} \geq 0 \quad(\alpha \neq \beta), \\
q_{\alpha \alpha}=-\sum_{\beta \neq \alpha} q_{\alpha \beta}
\end{gathered}
$$

The transition probabilities are given by:

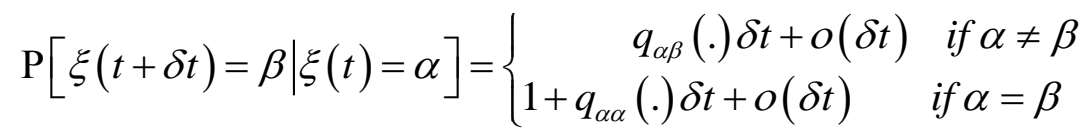

with $\lim _{\delta t \rightarrow 0} \frac{o(\delta t)}{\delta t}=0$ for all $\alpha, \beta \in B$.

The set of the feasible control policies $\Gamma(\alpha)$, including $u_{1}(\cdot)$ and $u_{2}(\cdot)$, depends on the stochastic process $\xi(t)$ and is given by:

$$
\Gamma(\alpha)=\left\{\left(u_{1}(\cdot), u_{2}(\cdot)\right) \in \mathfrak{R}^{2}, 0 \leq u_{1}(\alpha, \cdot) \leq u_{\max }^{1} \operatorname{Ind}\left\{\xi_{1}(t)=1\right\}, 0 \leq u_{2}(\alpha, \cdot) \leq u_{\max }^{2} \operatorname{Ind}\left\{\xi_{1}(t)=1\right\}\right\}
$$

where $\xi(t)=\alpha ; u_{\max }^{1}$ and $u_{\max }^{2}$ are the maximal production rates for $M_{1}$ and $M_{2}$, respectively, with

$$
\text { Ind }\{\Theta(\cdot)\}= \begin{cases}1 & \text { if } \Theta(\cdot) \text { is true } \\ 0 & \text { otherwise }\end{cases}
$$

Let $g(\cdot)$ be the cost rate defined as follow:

$$
g\left(\alpha, x_{1}, x_{2}\right)=c_{1}^{+} x_{1}^{+}+c_{2}^{+} x_{2}^{+}+c_{1}^{-} x_{1}^{-}+c_{2}^{-} x_{2}^{-}+c^{\alpha}+\left(d_{p}(t) \times C_{\text {disposal }}\right), \quad \forall \alpha \in B
$$

where $x_{i}^{+}=\max \left(0, x_{i}\right), x_{i}^{-}=\max \left(0,-x_{i}\right)$ and $\mathrm{c}^{\alpha}$ is a constant defined as follows:

$$
c^{\alpha}=c_{r}^{1} \operatorname{Ind}\{\xi(t)=2\}+c_{r}^{2} \operatorname{Ind}\{\xi(t)=3\}+\left(c_{r}^{1}+c_{r}^{2}\right) \cdot \operatorname{Ind}\{\xi(t)=4\}
$$


Our objective is to control the production rates $u_{1}(\cdot)$ and $u_{2}(\cdot)$ so as to minimize the expected discounted cost given by:

$$
J\left(\alpha, x_{1}, x_{2}\right)=\mathrm{E}\left\{\int_{0}^{\infty} e^{-\rho t} g\left(\alpha, x_{1}, x_{2}\right) d t \mid x_{1}(0)=x_{1}, x_{2}(0)=x_{2}, \xi(0)=\alpha\right\}
$$

where $\rho$ is the discount rate. The value function of such a problem is defined as follows:

$$
v\left(\alpha, x_{1}, x_{2}\right)=\inf _{\left(u_{1}(\cdot), u_{2}(\cdot)\right) \in \Gamma(\alpha)} J\left(\alpha, x_{1}, x_{2}\right) \quad \forall \alpha \in B
$$

In appendix $\mathrm{A}$, we present the properties of the value function $v($.$) given by equation (8) by$ showing that such a function satisfies the Hamilton-Jacobi-Bellman (HJB) equations. The properties of the value function and the way to obtain HJB equations can be found in Kenné et al. (2003). Such equations describe the optimality conditions for manufacturing and remanufacturing planning problems. Numerical methods used to solve the proposed optimality conditions are also presented in Appendix A. In the next Section, we provide a numerical example to illustrate the structure of the control policies.

\section{Analysis of results}

In this Section, we present a numerical example for the hybrid manufacturing/remanufacturing system presented in Section 3. The system capacity is described by a four states Markov process with the modes in $B=\{1,2,3,4\}$. We used the computational domains $D=G_{h_{1}} \times G_{h_{2}}$ such that:

$$
G_{h_{1}}=\left\{x_{1}:-20 \leq x_{1} \leq 40\right\}, \quad G_{h_{2}}=\left\{x_{2}:-20 \leq x_{2} \leq 40\right\}
$$

with $h_{1}=1$ and $h_{2}=1$. The manufacturing/remanufacturing system will be able to meet the customer demands (represented by the demand rate $d_{c}$ ), over an infinite horizon and reach a steady state if:

$$
\eta_{1}\left(u_{\max }^{1}+u_{\max }^{2}\right)+\eta_{2} u_{\max }^{1}+\eta_{3} u_{\max }^{2}>d_{c}
$$


where $\eta_{k}, k=1,2,3$, is the limiting probability of the system at mode $k$. Note that the limiting probabilities of modes $1,2,3$ and 4 (i.e., $\eta_{1}, \eta_{2}, \eta_{3}$ and $\eta_{4}$ ), are computed as follows:

$$
\eta \cdot Q(\cdot)=0 \quad \text { and } \quad \sum_{i=1}^{4} \eta_{i}=1
$$

where $\eta=\left(\eta_{1}, \eta_{2}, \eta_{3}, \eta_{4}\right)$; and $Q(\cdot)$ is the corresponding $4 \times 4$ transition rate matrix. Table 2 summarizes the parameters used in this paper. The feasibility condition given by equation (11) is satisfied for the chosen parameters if the raw material for the remanufacturing machine is always available (as discussed previously). We obtain a $6.6 \%$ availability of the system (i.e., $A V_{s}=6.6$ ), given by the following expression:

$$
A V_{s}=\frac{100}{d_{c}}\left(\eta_{1}\left(u_{\max }^{1}+u_{\max }^{2}\right)+\eta_{2} u_{\max }^{1}+\eta_{3} u_{\max }^{2}-d_{c}\right)
$$

The policy improvement technique is used to solve the system of equations (A.4)-(A.7), see appendix 1, for the data presented in table 2 with $d_{r}=d_{c} \times R_{r}$ where $R_{r}$ is a return rate.

The first scenario investigated in this paper, for which the return rate (backward direction) is defined as the quotient of the average returns $\mu_{R}$ and the average demands of serviceable products $\mu_{D}$ (i.e., $\left.{ }^{\top} R_{r}=\mu_{R} / \mu_{D}=d_{r} / d_{c}\right)$ provides the manufacturing and remanufacturing policies for $R_{r}=0.5 \mu_{D}$ (i.e., $d_{r}=d_{c} \times 50 \%$ ). As a result, the value function representing the cost and the production rates of manufacturing and remanufacturing machines are obtained and depicted in Figures 3, 4a and 4b (for manufacturing), 5a and 5b (for remanufacturing), respectively.

The production rates of the manufacturing and remanufacturing machines in their operational mode (i.e., mode 1) are presented in Figures 4 and 5. The obtained manufacturing and remanufacturing policies in modes 2 and 3 recommend to set the manufacturing rate (mode 2) or the remanufacturing rate (mode 3 ) to their maximal values given that the hybrid system is feasible only at mode 1 . There is no production in mode 4 given that both machines are down. For the manufacturing policy, Figure 4 shows that there is no need to produce parts, using $M_{1}$ for comfortable stock levels. Then the production rate is set to zero when the stock level of manufactured products is greater than 25 products as illustrated in figure 6 . The structure of the remanufacturing control policy is similar to the one of the manufacturing process with a different 
threshold level. As illustrated in Figure 5, the production rate is set to zero when the stock level of remanufacturing products is greater than 32 products. The threshold values of 25 and 32 products for manufacturing and remanufacturing are obtained from the numerical resolution of equations (A.4) to (A.7) and well illustrated in Figures 4(b) and 5(b). The quantified feedback policy obtained for this basic case and its implementation are illustrated in figure 6. Recall that, in the considered forward-reverse logistics network, the remanufactured process brings returned products back to as new condition. The bigger value of the remanufacturing threshold level, compared to the manufacturing threshold level, is mainly due to the fact that the considered mean time to failure of $M_{1}$ is greater than the mean time to failure of $M_{2}$ (i.e., $\mathrm{MTTF}_{M 1}>\mathrm{MTTF}_{M 2}$ or $\left.q_{10}^{1}<q_{10}^{2}\right)$.

From the obtained results, and based on the illustration of Figure 6, the computational domain is divided into three regions where the optimal production control policy consists of one of the following rules:

1. Set the production rate of the manufacturing or remanufacturing system to its maximal value when the current stock level is under the corresponding threshold value $\left(Z_{1}^{\alpha}\right.$ for manufacturing machine $M_{1}$ and $Z_{2}^{\alpha}$ for remanufacturing machine $M_{2}$ ).

2. Set the production rate of $M_{1}$ to the demand rate $d_{m}$ when the current stock level of manufactured products is equal to $Z_{1}^{\alpha}$. Set also the production rate of $M_{2}$ to the demand rate $d_{r}$ when the current stock level of remanufactured products is equal to $Z_{2}^{\alpha}$.

3. Set the production rates of manufacturing or remanufacturing machines to zero when their current stock levels are larger than $Z_{1}^{\alpha}$ or $Z_{2}^{\alpha}$.

The control policy obtained is an extension to the so-called hedging point policy given that the previous three rules respect the structure presented in Akella and Kumar (1986). Thus, the production policy for the manufacturing and remanufacturing at mode $\alpha=1$ are given respectively by:

$$
u_{1}\left(x_{1}, x_{2}, 1\right)=\left\{\begin{array}{lc}
u_{\max }^{1} & \text { if } x_{1}(\cdot)<Z_{1}^{1} \\
d_{c}-d_{r} & \text { if } x_{1}(\cdot)=Z_{1}^{1} \\
0 & \text { otherwise }
\end{array}\right.
$$


and

$$
u_{2}\left(x_{1}, x_{1}, 1\right)= \begin{cases}u_{\max }^{2} & \text { if } x_{2}(\cdot)<Z_{2}^{1} \\ d_{r} & \text { if } x_{2}(\cdot)=Z_{2}^{1} \\ 0 & \text { otherwise }\end{cases}
$$

Using the control policies given by equations (13) and (14), the company will minimize the total cost due to remanufacturing so that eventually it can maximise its total profit.

The previous results have been obtained for a return rate equal 50\%. Let us first confirm the structure of the control policies through a sensitivity analysis; and then observe the system for different return rates. The aim of the sensitivity analysis is also to validate and illustrate the usefulness of the model developed in this paper.

\section{Sensitivity analysis}

Sensitivity analyses are conducted on backlog cost parameters to gain insight into the proposed stochastic model. The proposed model is also validated in this Section through a set of experimental data reflecting practical industrial situation by considering a return rate different from the one used in the previous Section. Extensions, based on some assumptions of the developed mathematical model, are discussed in the next Section.

We performed a couple of experiments using the numerical example presented previously. The results shown in Tables 3, 4, 5 and 6 represent two different situations in forward-reverse logistics system analysis presented below for returned rates set to $50 \%$ and $25 \%$ respectively. Figure 7, Tables 3 and 4 are based on the variation of manufacturing/remanufacturing backlog costs for a $50 \%$ return rate.

The corresponding trend of variation for the threshold levels (manufacturing and remanufacturing) and the incurred costs (represented by the average value function $\left.\bar{v}\left(Z_{1}^{2}, Z_{2}^{1}\right)\right)$ is illustrated in Figure 7(a) and 7(b), respectively. One can observe that when the backlog costs $c_{1}^{-}$and $c_{2}^{-}$increase, the threshold values $Z_{1}^{1}$ and $Z_{2}^{1}$ also increase.

The overall cost also increases as well. In Tables 3 and 4, the experiment corresponding to $\left(c_{1}^{-}, c_{2}^{-}\right)=(10,10),\left(Z_{1}^{2}, Z_{2}^{1}\right)=(13,18)$ and $\bar{v}(13,18)=5294$ is highlighted and is considered as a basic case of the first block of backlog costs variations (i.e., for a return rate of 50\%). The parameters of the control policy move as predicted from a practical view point. 
The sensitivity analysis performed in this paper, validates the proposed approach and shows the usefulness of the proposed model given that the control policy is well defined by the equations (13)-(14) and parameters obtained from results analysis. We also conducted a similar sensitivity analysis for a return rate of $25 \%$ given that we assumed a known return rate instead of trying to find it throw an optimization problem. Figure 7, Tables 5 and 6 are based on the variation of manufacturing/remanufacturing backlog costs for a $25 \%$ return rate. As in the case of $50 \%$ return rate, in Tables 5 and 6 , the experiment corresponding to $\left(c_{1}^{-}, c_{2}^{-}\right)=(20,20)$, $\left(Z_{1}^{2}, Z_{2}^{1}\right)=(45,7)$ and $\bar{v}(13,18)=12725$ is highlighted and is considered as a basic case of the second block of backlog costs variations (i.e., for a return rate of $25 \%$ ).

The corresponding trend of variation for the threshold levels (manufacturing and remanufacturing) and the incurred costs (represented by the average value function $\left.\bar{v}\left(Z_{1}^{2}, Z_{2}^{1}\right)\right)$ is illustrated in Figure 8(a) and 8(b) respectively. When the backlog costs $c_{1}^{-}$and $c_{2}^{-}$increase, the threshold values $z_{1}$ and $z_{2}$ also increase as in the case of $50 \%$ return rate. Due to the fact that the return rate is $25 \%$, the manufacturing and remanufacturing stock levels converge to 62 and 9 serviceable parts as their corresponding backlog cost is large.

The restriction that the remanufacturing process contributes just for $25 \%$ of the overall production give a large threshold level for the $M_{1}$ to ensure sufficient serviceable parts to hedge against future failures of the machines.

\section{Discussions and extensions}

The proposed hybrid manufacturing/remanufacturing model can be applicable to the various industries after specific customization. However, as the proposed model is introduced with restrictive assumptions, many future works are accordingly needed. Above all, the proposed model with backward information (remanufacturing) can be extended by adopting more industry practices and so the relevant complex mathematical model need to be developed. Since the proposed model is formulated as a markovian stochastic optimal model, the computational burden for optimal solution increases exponentially as the size of problem increases (number of machines, number of products, uncertainty on product demands and returns). Thus, in the future, 
an efficient heuristic algorithm needs to be developed in order to solve the large-scale problems in real industrial environment.

Recall that, for the system considered previously and related to a one manufacturing machine, one remanufacturing machine and one-product, the control policy described by equations (13) and (14) is completely known for given $Z_{1}^{\alpha}$ and $Z_{2}^{\alpha}$ with $\alpha \in\{1,2,3\}$ For a more complex manufacturing system consisting of $\quad m$ machines for manufacturing, $n$ machines for remanufacturing, producing $p$ different part types, the control policy depends on the parameters $Z_{k i}^{\alpha}$, and $Z_{k j}^{\alpha}$, for $k \in\{1,2 \cdots, p\}, \quad i \in\{1,2 \cdots, m\}, \quad j \in\{1,2 \cdots, n\}$. The solution of the HJB equations (as in equation (A.1)) is almost impossible for large $m, n$ and $p$ since the dimension of the numerical scheme to be implemented increase exponentially with the complexity of the system. Such a dimension is given by the following equation:

$$
\operatorname{Dim}=2^{m \times n} \times 3^{m \times n \times 2 p} \times \prod_{j=1}^{p} N_{h}\left(x_{1 j}\right) \times \prod_{j=1}^{p} N_{h}\left(x_{2 j}\right)
$$

where $N_{h}\left(x_{k j}\right)=\operatorname{card}\left[G_{h}\left(x_{k j}\right)\right] \quad$ with $\quad k=1$ for manufacturing inventories and $k=2$ for remanufacturing inventories. The numerical grids for the manufacturing and remanufacturing stock levels are $G_{h}\left(x_{1 j}\right)$ and $G_{h}\left(x_{2 j}\right)$, respectively. Each machine has two modes (i.e., $2^{m \times n}$ modes for $m \times n$ machines) and its production rate can take three values, namely maximal production rate, demand rate and zero for manufactured and remanufactured products (i.e., $3^{m \times n \times 2 p}$ possibilities for $m$-manufacturing machines, $n$-remanufacturing machines products an $p$-products system). For example, in the case of 12 machines, 5 types of products $(m=12, n=5)$, with $N_{h}\left(x_{1 j}\right)=100, N_{h}\left(x_{2 j}\right)=100, j=1, \cdots, 5$, from equation (15), we have:

$$
\operatorname{Dim}=2^{12} \times 3^{12 \times 10} \times 100^{5} \times 100^{5}=7.36 \times 10^{80}
$$

The related numerical algorithm cannot be implemented on today computers. Such problems are classified in the control literature as complex problems (Gershwin (1990)). For the aforementioned complex problem (i.e., with $m, n$ and $p$ ), a hierarchical control approach as in Kenné and Boukas (2003) or a combination of the control theory and the simulation based experimental design as in Gharbi and Kenné (2003) can be used to obtain a near optimal control policy. The use of simulation is more appropriate in this context because it provides a tool to understand how the system behaves by carrying out «what-if» assessments and to identify which 
factors are more important for further more detailed analysis (response surface analysis and optimization). This could give the possibility to develop a more general model in reverse logistic network including capacity limits, multi-product management and uncertainty on product demands and returns.

\section{Conclusion}

The number of applications and scientific publications in the field of reverse logistics has been steadily growing, reflecting the increasing importance of this subject, mainly as a result of society's accrued environment awareness and search for economic productivity. However, taking a closer look to the dynamic characteristic of the production planning problems, one can notice that reported work is mostly based on non machine-dynamic models and thus, general models are missing, in particular models that relate reverse and forward chains. In this paper, the production planning model of a hybrid manufacturing/remanufacturing system in reverse logistics has been proposed in a continuous time stochastic context. We developed the stochastic optimization model of the considered problem with two decision variables (production rates of manufacturing and remanufacturing machines) and two state variables (stock levels of manufactured and remanufactured products). By controlling both the manufacturing and remanufacturing rates, we obtained a near optimal control policy of the system through numerical techniques yielding straightforward decision rules. We illustrated and validated the proposed approach using a numerical example and a sensitivity analysis. We finally discuss the extension of the proposed model to the case of a forward-reverse logistics network involving multiple products, multiple machines and uncertainty on product demands and returns.

\section{Acknowledgements}

The authors want to thank two anonymous referees whose critics and suggestions contributed to significantly increase the quality of this paper. 


\section{Appendix A}

\section{Optimality conditions and numerical approach}

Regarding the optimality principle, we can write the HJB equations as follows:

$$
\rho v\left(x_{1}, x_{2}, \alpha\right)=\min _{\left(u_{1}, u_{2}\right) \in \Gamma(\alpha)}\left\lfloor g\left(x_{1}, x_{2}, \alpha\right)+\left(u_{1}-d_{m}\right) v_{x 1}(\cdot)+\left(u_{2}-d_{r}\right) v_{x 2}(\cdot)+\sum_{\beta \in B} \lambda_{\alpha \beta}(\cdot)[v(\beta, \varphi(x, \beta))-v(\alpha, a, x)]\right\rfloor
$$

The optimal control policy $\left(u_{1}^{*}(\cdot), u_{2}^{*}(\cdot)\right)$ denotes a minimiser over $\Gamma(\alpha)$ of the right hand side of equation (9). This policy corresponds to the value function described by equation (7). Then, when the value function is available, an optimal control policy can be obtained as in equation (9). However, an analytical solution of equations (A.1) is almost impossible to obtain. The numerical solution of the HJB equations (9) is a challenge which was considered insurmountable in the past. Boukas and Haurie (1990) showed that implementing Kushner's method can solve such a problem in the context of production planning.

Let us now develop the numerical methods for solving the optimality conditions given by equation (9). Such methods are based on the Kushner approach as in Kenné et al. (2003), Hajji et al. (2009) and references therein. The main idea behind this approach consists of using an approximation scheme for the gradient of the value function $v\left(x_{1}, x_{2}, \alpha\right)$. Let $h_{1}$ and $h_{2}$ denote the length of the finite difference interval of the variables $x_{1}$ and $x_{2}$ respectively. The value function $v\left(x_{1}, x_{2}, \alpha\right)$ is approximated by $v^{h}\left(x_{1}, x_{2}, \alpha\right)$ and $v_{x_{i}}\left(x_{1}, x_{2}, \alpha\right)$ as in equation (10).

$$
v_{x_{i}}\left(x_{1}, x_{2}, \alpha\right) \times\left(u_{i}-d_{i}\right)= \begin{cases}\frac{1}{h_{i}}\left(v^{h}\left(\cdot, x_{i}+h_{i}, \alpha\right)-v^{h}\left(x_{1}, x_{2}, \alpha\right)\right) \times\left(u_{i}-d_{i}\right) & \text { if } u_{i}-d_{i}>0 \\ \frac{1}{h_{x}}\left(v^{h}\left(x_{1}, x_{2}, \alpha\right)-v^{h}\left(\cdot, x_{i}-h_{i}, \alpha\right)\right) \times\left(u_{i}-d\right) & \text { otherwise }\end{cases}
$$

with $i=1,2, d_{1}=d_{m}$ and $d_{2}=d_{r}$. With approximations given by equation (10) and after a couple of manipulations, the HJB equations can be rewritten as follows:

$$
v^{h}\left(x_{1}, x_{2}, \alpha\right)=\min _{\left(u_{1}, u_{2 r}\right) \in \Gamma^{h}(\alpha)}\left\{\frac{g\left(x_{1}, x_{2}, \alpha\right)}{\Omega_{h}^{\alpha}\left(1+\rho / \Omega_{h}^{\alpha}\right)}+\frac{1}{\left(1+\rho / \Omega_{h}^{\alpha}\right)}\left(\begin{array}{l}
p_{x_{1}}^{ \pm}(\alpha) v^{h}\left(x_{1} \pm h_{x_{1}},, \alpha\right)+p_{x_{2}}^{ \pm}(\alpha) v^{h}\left(\cdot, x_{2} \pm h_{x_{2}}, \alpha\right) \\
+\sum_{\beta \neq \alpha} p^{\beta}(\alpha) v^{h}\left(x_{1}, x_{2}, \alpha\right)
\end{array}\right)\right\}
$$


where $\Gamma^{h}(\alpha)$ is the discrete feasible control space or the so-called control grid and the other terms used in equation (A.3) are defined as follows:

$$
\begin{gathered}
\Omega_{h}^{\alpha}=\left|\lambda_{\alpha \alpha}\right|+\frac{\left|u_{1}-d_{c}\right|}{h_{1}}+\frac{\left|u_{2}-d_{r}\right|}{h_{2}} \\
p_{x_{i}}^{+}(\alpha)= \begin{cases}\frac{u_{i}-d_{i}}{h_{x} \Omega_{h}^{\alpha}} & \text { if } \quad u_{i}-d_{i}>0 \\
0 & \text { otherwise }\end{cases} \\
p_{x_{i}}^{-}(\alpha)= \begin{cases}\frac{d i-u i}{h_{i} \Omega_{h}^{\alpha}} & \text { if } u_{i}-d_{i} \leq 0 \\
0 & \text { otherwise }\end{cases} \\
p^{\beta}(\alpha)=\frac{\lambda_{\alpha \beta}}{\Omega_{h}^{\alpha}}
\end{gathered}
$$

The system of equations (A.3) can be interpreted as the infinite horizon dynamic programming equation of a discrete-time, discrete-state decision process. Noting that $p_{x_{1}}^{+}(\alpha)+p_{x_{2}}^{+}(\alpha)+p_{x_{1}}^{-}(\alpha)+p_{x_{2}}^{-}(\alpha)+\sum_{\beta \neq \alpha} p^{\beta}(\alpha)=1$, the terms $p_{x_{i}}^{+}(\alpha), p_{x_{i}}^{-}(\alpha)$ and $p^{\beta}(\alpha)$, for all $\beta \neq \alpha$, can be considered as transition probabilities for a controlled Markov chain on a discrete state space representing the control grid to be considered for the numerical solution of HJB equations. The term $1 /\left(1+\rho / \Omega_{h}^{\alpha}\right)$, for all $\alpha \in B$, corresponds to a positive discount factor which is bounded away from 1 . The obtained discrete event dynamic programming can be solved using either policy improvement or successive approximation methods. In this paper, we use the policy improvement technique to obtain a solution of the approximating optimization problem. The algorithm of this technique can be found in Kushner and Dupuis (1992).

The discrete dynamic programming equation (A.3) yields the following four equations:

$$
v^{h}\left(x_{1}, x_{2}, 1\right)=\min _{\left(u_{1}, u_{2}\right) \in \Gamma^{h}(1)}\left\{\frac{g\left(1, x_{1}, x_{2}, u_{1}, u_{2}\right)}{\Omega_{h}^{1}\left(1+\rho / \Omega_{h}^{1}\right)}+\frac{1}{\left(1+\rho / \Omega_{h}^{1}\right)}\left(\begin{array}{l}
p_{x 1}^{ \pm}(1) v^{h}\left(x_{1} \pm h_{1}, x_{2}, 1\right)+p_{x 2}^{ \pm}(1) v^{h}\left(x_{1}, x_{2} \pm h_{2}, 1\right) \\
+p^{2}(1) v^{h}\left(x_{1}, x_{2}, 2\right)+p^{3}(1) v^{h}\left(x_{1}, x_{2}, 3\right)
\end{array}\right)\right\}
$$




$$
v^{h}\left(x_{1}, x_{2}, 2\right)=\min _{u_{1} \in \Gamma^{h}(2)}\left\{\frac{g\left(2, x_{1}, x_{2}, u_{1}, 0\right)}{\Omega_{h}^{2}\left(1+\rho / \Omega_{h}^{2}\right)}+\frac{1}{\left(1+\rho / \Omega_{h}^{2}\right)}\left(\begin{array}{l}
p_{x 1}^{ \pm}(2) v^{h}\left(x_{1} \pm h_{1}, x_{2}, 2\right)+p_{x 2}^{-}(2) v^{h}\left(x_{1}, x_{2}-h_{2}, 2\right) \\
+p^{1}(2) v^{h}\left(x_{1}, x_{2}, 1\right)+p^{4}(2) v^{h}\left(x_{1}, x_{2}, 4\right)
\end{array}\right)\right\}
$$

$$
\begin{gathered}
v^{h}\left(x_{1}, x_{2}, 3\right)=\min _{u_{2} \in \Gamma^{h}(3)}\left\{\frac{g\left(3, x_{1}, x_{2}, 0, u_{2}\right)}{\Omega_{h}^{3}\left(1+\rho / \Omega_{h}^{3}\right)}+\frac{1}{\left(1+\rho / \Omega_{h}^{3}\right)}\left(\begin{array}{l}
p_{x 1}^{-}(3) v^{h}\left(x_{1}-h_{1}, x_{2}, 3\right)+p_{x 2}^{ \pm}(3) v^{h}\left(x_{2} \pm h_{2}, 3\right) \\
+p^{1}(3) v^{h}\left(x_{1}, x_{2}, 1\right)+p^{4}(3) v^{h}\left(x_{1}, x_{2}, 4\right)
\end{array}\right)\right\} \\
v^{h}\left(x_{1}, x_{2}, 4\right)=\left\{\frac{g\left(3, x_{1}, x_{2}, 0,0\right)}{\Omega_{h}^{4}\left(1+\rho / \Omega_{h}^{4}\right)}+\frac{1}{\left(1+\rho / \Omega_{h}^{4}\right)}\left(\begin{array}{l}
p_{x 1}^{-}(4) v^{h}\left(x_{1}-h_{1}, x_{2}, 4\right)+p_{x 2}^{-}(4) v^{h}\left(x_{1}, x_{2}-h_{2}, 4\right) \\
+p^{2}(4) v^{h}\left(x_{1}, x_{2}, 2\right)+p^{3}(4) v^{h}\left(x_{1}, x_{2}, 3\right)
\end{array}\right)\right\}
\end{gathered}
$$

(A.7) 


\section{$\underline{\text { References }}$}

Akella, R., Kumar, P. R., Optimal Control of Production Rate in a Failure Prone Manufacturing System, IEEE Trans. on Automatic Control, AC 31, 116-126, 1986

* Amezquita, T. and Bras, B., Lean remanufacture of an Automobile Clutch, Proceedings of First International Working Seminar on Reuse, Eindhoven, The Netherlands, p 6, 1996

* Bostel, N., Dejax, P., Lu, Z., The Design, Planning and Optimization of Reverse Logistic Networks, in Logistics Systems: Design and Optimization, A. Langevin, D. Riopel, editors, Springer, 171-212, 2005

* Boukas, E.K., Haurie, A., Manufacturing Flow Control and Preventive Maintenance: A Stochastic Control Approach, IEEE Trans. on Automatic Control, 33, 1024-1031, 1990

* Chung, S. L., Wee, H.M., Po-Chung, Y., Optimal Policy for a Closed-Loop Supply Chain Inventory System With Remanufacturing, Mathematical and Computer Modelling, 6, 867881,2008

* Dobos, I., Optimal Production-Inventory Strategies for a HMMS-Type Reverse Logistics System, International Journal of Production Economics, 81-82(11), 351-360, 2003

* De Brito, M. P., Dekker, R., Flapper S. D. P., Reverse Logistics - a Review of Case Studies, ERIM Report Series Reference No. ERS-2003-012-LIS, 2003

* Dehayem, N.F.I., Kenné, J.P., Gharbi, A., Hierarchical Decision Making in Production and Repair/Replacement Planning with Imperfect Repairs Under Uncertainties, European Journal of Operational Research, 198( 1), 173-189, 2009

* Dekker, R., Fleismann, M., Interfuth, K., Van Wassenhove L., edts., Reverse Logistics. Quantitative models for closed-loops supply chains, 2004

* Dong-Ping Song., Production and Preventive Maintenance Control in a Stochastic Manufacturing System, International Journal of Production Economics, 19(1): 101-111, 2009

* El-Sayed, M., Afia, N., El-Kharbotly, A., A Stochastic Model for Forward-Reverse Logistics Network Design Under Risk, Computers \& Industrial Engineering, In Press, 2008

* Fleischmann, M., Bloemhof-Ruwaard, J.M., Dekker R., Van der, L.E., Van Nunen, J. A. E. E., Van Wassenhove, L.N., Quantitative Models for Reverse Logistics: A review, European Journal of Operational Research, 103(1), 1-17,1997

* Gharbi, A., Kenné, J.P., Optimal Production Control Problem in Stochastic Multiple- Product Multiple-Machine Manufacturing Systems, IIE transactions, 35, 941-952, 2003

* Gharbi, A., Pellerin, R., Sadr, J., Production Rate Control for Stochastic Remanufacturing Systems, International Journal of Production Economics, 112(1), 37-47, 2008

* Gershwin, S. B., Manufacturing Systems Engineering, Prentice Hall, 1994

* Geyer, R., Jackson, T., Supply Loops and Their Constraints: The Industrial Ecology of Recycling and Reuse. California Management Review 46 (2), 55-73, Winter 2004. 
* Guide V.D.R. and Van Vassenhove, L.N., Closed-Loop Supply Chains, Feature Issue (Part 1), Production and Operations Management, Vol. 15, No 3, 2006

* Guide V.D.R. and Van Vassenhove, L.N., Closed-Loop Supply Chains, Feature Issue (Part 2), Production and Operations Management, Vol. 15, No 4, 2006

* Hajji, A., Gharbi, A., Kenné, J. P., Joint Replenishment and Manufacturing Activities Control in Two Stages Unreliable Supply Chain, International Journal of Production Research, 47(12), 3231-3251, 2009

* Jorjani, S., Leu, J., Scott, C., Model for The Allocation of Electronics Components to Reuse Options, International Journal of Production Research, 42(6), 1131-1145, 2004

* Kenné, J.P., Boukas, E. K., Hierarchical Control of Production and Maintenance Rates in Manufacturing Systems Journal of Quality in Maintenance Engineering, 9, 66-82, 2003

* Kenné, J.P., Boukas, E.K., Gharbi, A., Control of Production and Corrective Maintenance Rates in a Multiple-Machine, Multiple-Product Manufacturing System, Mathematical and Computer Modelling, 38, 351-365, 2003

* Kibum, K., Iksoo, S. Juyong, K., Bongju, J., Supply Planning Model for Remanufacturing System in Reverse Logistics Environment, Computers \& Industrial Engineering, 51( 2), 279287,2006

* Kiesmuller, G. P., Scherer, C. W., Computational Issues in a Stochastic Finite Horizon One Product Recovery Inventory Model, European Journal of Operational Research, 146( 3), 553579,2003

* Kushner, H.J., Dupuis, J., Numerical Methods for Stohastic Control Problems in Continuous Time, Springer-Verlag, 1992

* Lund, R., The Remanufacturing Industry: Hidden Giant, Boston, Massachusetts: Boston University, 1996

* Ostlin, J., Sundin, E., Bjorkman, M., Importance of Closed-Loop Supply Chain Relationships for Product Remanufacturing, International Journal of Production Economics, Volume 115, 336-348, 2008

* Pellerin, R., Sadr, J., Gharbi, A., Malhamé ,R., A Production Rate Control Policy for Stochastic Repair and Remanufacturing Systems, International Journal of Production Economics, In Press, 2009

* Rishel, R., Dynamic Programming and Minimum Principles for Systems With Jump Markov Disturbances, SIAM journal on Control, 13, 338-371, 1975

* Rogers, D. S., Tibben-Lembke, R.S., Going backwards: reverse logistics trends and practices, Center for Logistics Management, University of Nevada, Reno, Reverse Logistics Executive Council, 1998

* Salema, M. I. G., Barbosa-Povoa, Ana Paula, Novais, A. Q., An Optimization Model for the Design of a Capacitated Multi-Product Reverse Logistics Network With Uncertainty, European Journal of Operational Research, 179(3), 1063-1077, 2007 
* Seaver, W.B., Design Considerations for Remanufacturability, Recyclability and Reusability and Reusability of User Interface Modules, Proceedings of IEEE International Symposium on Electronics and the Environment, (IEEE-94), San Francisco, CA, USA, 241-245, 1994

* Seierstad, A., Sydsaeter, K., Optimal Control Theory with Economic Applications. NorthHolland, Amsterdam, 1987

* Sundin, E. and Bras B., Making Functional Sales Environmentally and Economically Beneficial through Product Remanufacturing. Journal of Cleaner Production, Vol. 13(9), pp 913-925, 2005

* Thierry, M.C., M. Salomon, M., Van Nunen, J., Van Wassenhove, L., Strategic Issues in Product Recovery Management, California Management Review 37, 114-135, 1995

* Verter, V., Boyaci, T., edts, Special issue on Reverse Logistics, Computers and Operations Research, 34, 295-298. 


\begin{tabular}{|c|c|c|c|c|}
\hline$\zeta_{1}(t)$ & 1 & 1 & 0 & 0 \\
\hline$\zeta_{2}(t)$ & 1 & 0 & 1 & 0 \\
\hline$\zeta(t)$ & 1 & 2 & 3 & 4 \\
\hline \multicolumn{2}{|c|}{$q_{12}=q_{10}^{2}$} & \multicolumn{2}{|c|}{$q_{13}=q_{10}^{1}$} & $q_{21}=q_{01}^{1}$ \\
\hline \multicolumn{2}{|c|}{$q_{34}=q_{01}^{2}}$, & \multicolumn{2}{|c|}{$q_{24}=q_{10}^{1}$} & $q_{42}=q_{01}^{1}$ \\
\hline
\end{tabular}

Table 1. Manufacturing/remanufacturing transition rates 


\begin{tabular}{|c|c|c|c|c|c|c|c|c|c|c|c|}
\hline$c_{1}^{+}$ & $c_{2}^{+}$ & $c_{1}^{-}$ & $c_{2}^{-}$ & $u_{\max }^{1}$ & $u_{\max }^{2}$ & $q_{10}^{1}$ & $q_{10}^{2}$ & $q_{01}^{1}$ & $q_{01}^{2}$ & $d_{c}$ & $\rho$ \\
\hline 1 & 1 & 50 & 50 & 1 & 0.9 & 0.02 & 0.03 & 0.75 & 0.75 & 0.75 & 0.01 \\
\hline
\end{tabular}

Table 2. Parameters of the numerical example (basic case) 


\begin{tabular}{|c|c|c|c|c|c|c|c|c|c|c|c|c|}
\hline$c_{1}^{-}$ & 2 & 5 & $\mathbf{1 0}$ & 20 & 30 & 40 & 50 & 60 & 70 & 80 & 90 & 100 \\
\hline$z_{1}$ & 3 & 9 & $\mathbf{1 3}$ & 19 & 22 & 23 & 24 & 25 & 25 & 26 & 26 & 26 \\
\hline $\bar{v}\left(Z_{1}^{2}, Z_{2}^{1}\right)$ & 4802 & 5048 & $\mathbf{5 2 9 4}$ & 5590 & 5806 & 5973 & 6102 & 6158 & 6175 & 6185 & 6187 & 6187 \\
\hline
\end{tabular}

Table 3. Sensitivity analysis for the manufacturing holding cost with a 50\% return rate 


\begin{tabular}{|c|c|c|c|c|c|c|c|c|c|c|c|c|}
\hline$c_{2}^{-}$ & 2 & 5 & $\mathbf{1 0}$ & 20 & 30 & 40 & 50 & 60 & 70 & 80 & 90 & 100 \\
\hline$z_{2}$ & 6 & 14 & $\mathbf{1 8}$ & 24 & 28 & 30 & 32 & 33 & 33 & 34 & 34 & 34 \\
\hline $\bar{v}\left(Z_{1}^{2}, Z_{2}^{1}\right)$ & 4615 & 4926 & $\mathbf{5 2 9 4}$ & 5735 & 6032 & 6263 & 6453 & 6553 & 6600 & 6650 & 6675 & 6680 \\
\hline
\end{tabular}

Table 4. Sensitivity analysis for the remanufacturing holding cost with a 50\% return rate 


\begin{tabular}{|c|c|c|c|c|c|c|c|c|c|c|c|c|}
\hline$c_{1}^{-}$ & 2 & 5 & 10 & $\mathbf{2 0}$ & 30 & 40 & 50 & 60 & 70 & 80 & 90 & 100 \\
\hline$z_{1}$ & 13 & 24 & 34 & $\mathbf{4 5}$ & 51 & 56 & 59 & 61 & 62 & 62 & 62 & 62 \\
\hline $\bar{v}\left(Z_{1}^{2}, Z_{2}^{1}\right)$ & 11189 & 11637 & 12116 & $\mathbf{1 2 7 2 5}$ & 13150 & 134480 & 13700 & 13850 & 13900 & - & - & - \\
\hline
\end{tabular}

Table 5. Sensitivity analysis for the manufacturing holding cost with a $25 \%$ return rate 


\begin{tabular}{|c|c|c|c|c|c|c|c|c|c|c|c|c|}
\hline$c_{2}^{-}$ & 2 & 5 & 10 & $\mathbf{2 0}$ & 30 & 40 & 50 & 60 & 70 & 80 & 90 & 100 \\
\hline$z_{2}$ & 0 & 1 & 4 & $\mathbf{7}$ & 8 & 9 & 9 & 9 & 9 & 9 & 9 & 9 \\
\hline $\bar{v}\left(Z_{1}^{2}, Z_{2}^{1}\right)$ & 12700 & 12713 & 12718 & $\mathbf{1 2 7 2 5}$ & 12730 & 12735 & 12735 & - & - & - & - & - \\
\hline
\end{tabular}

Table 6. Sensitivity analysis for the remanufacturing holding cost with a $25 \%$ return rate 


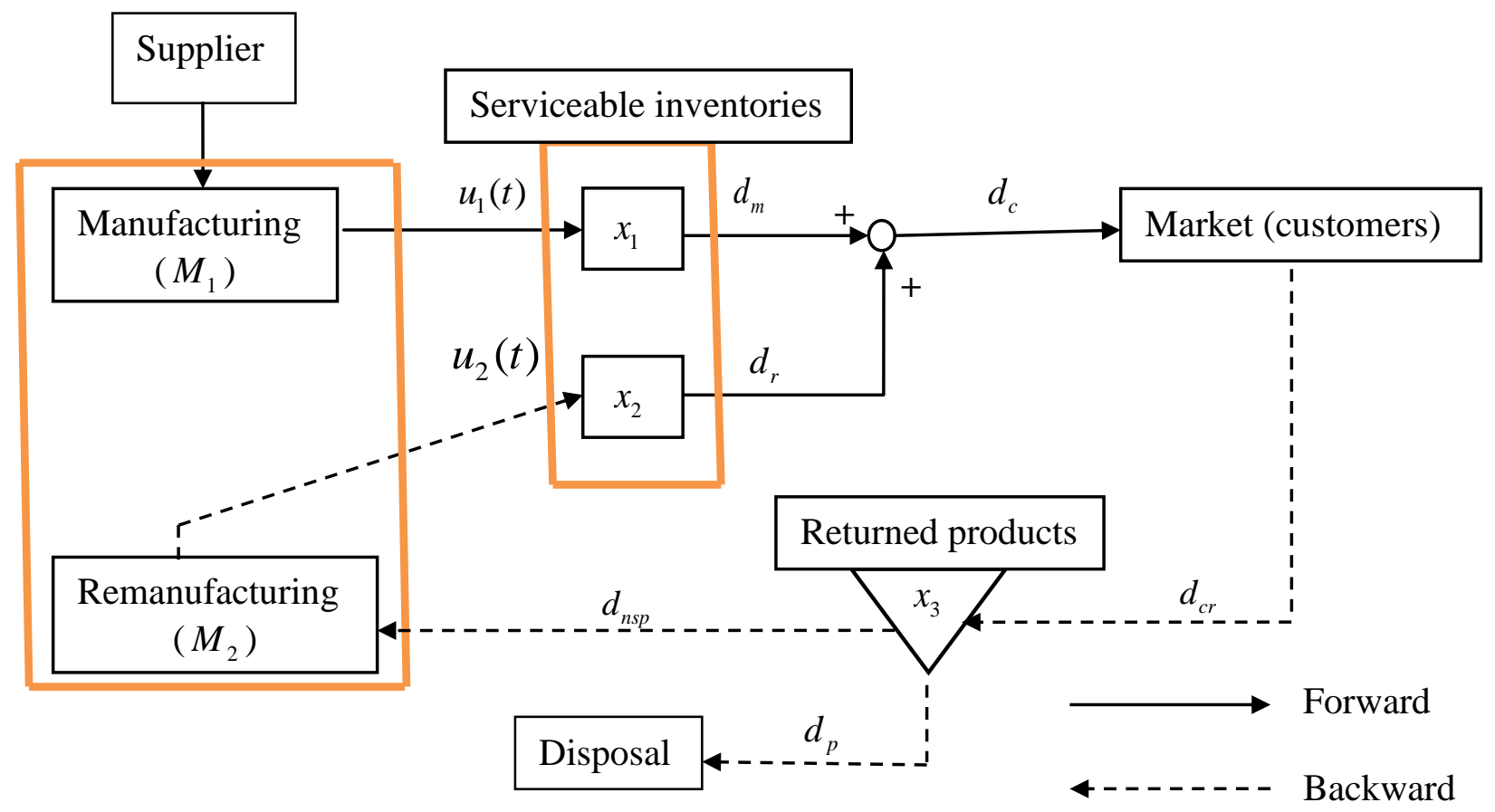

Figure 1. Material flow of the system 


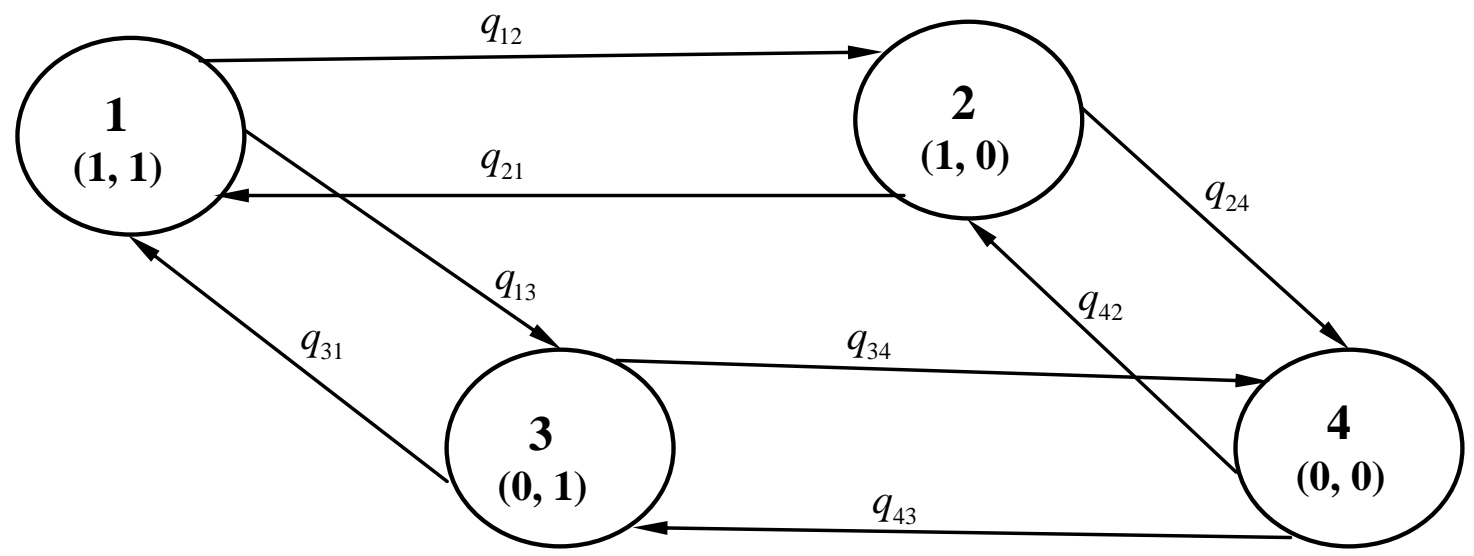

Figure 2. States transition diagram of the considered system 


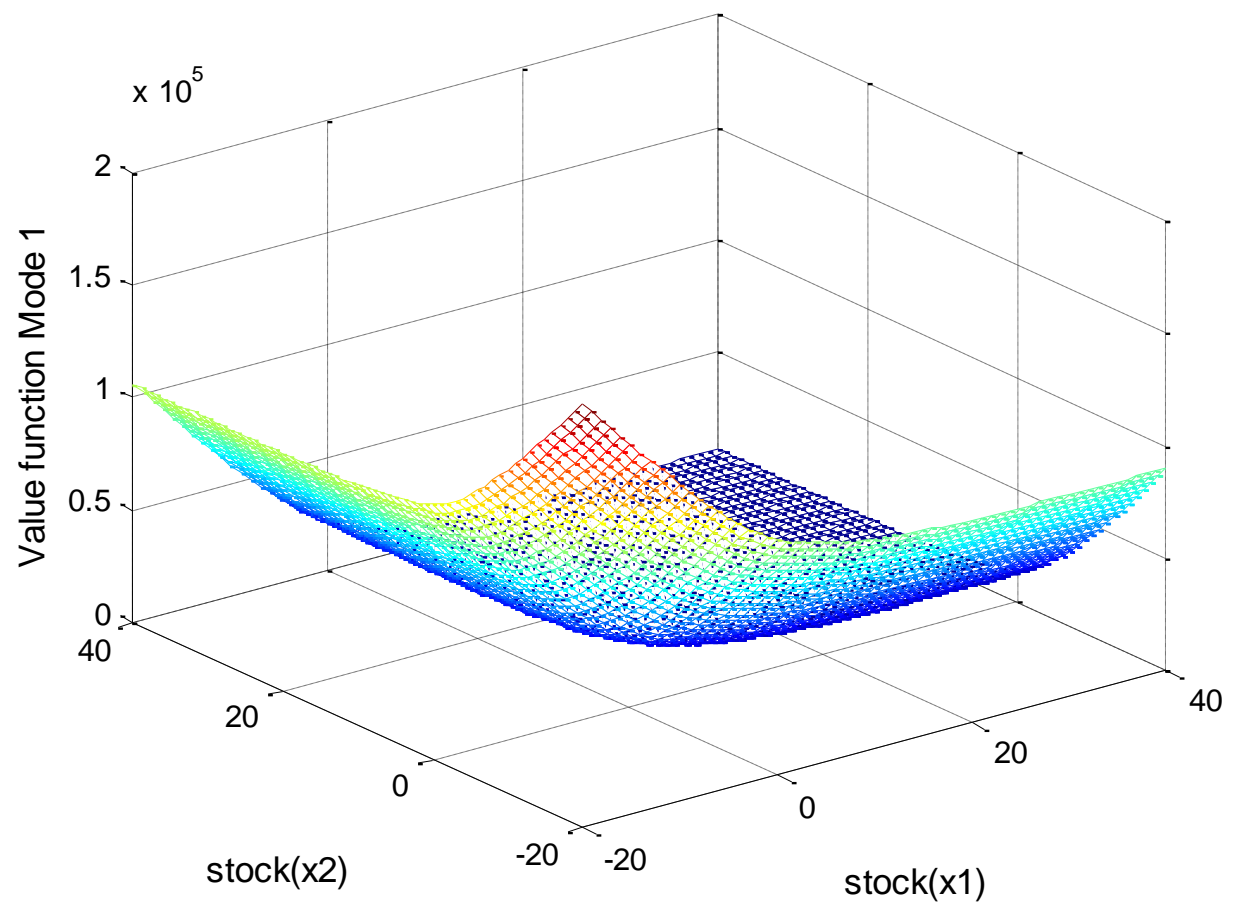

Figure 3. Value function representing the cost at mode 1 


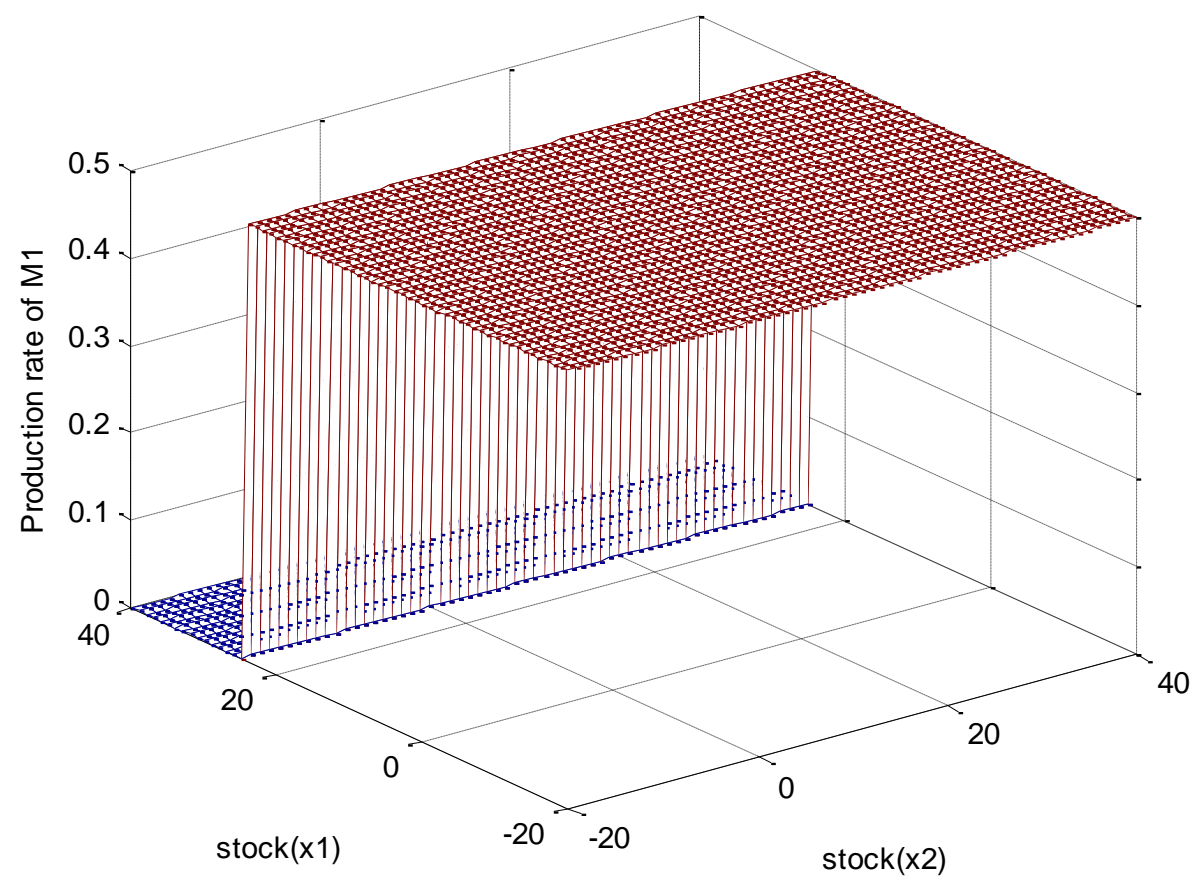

(a)

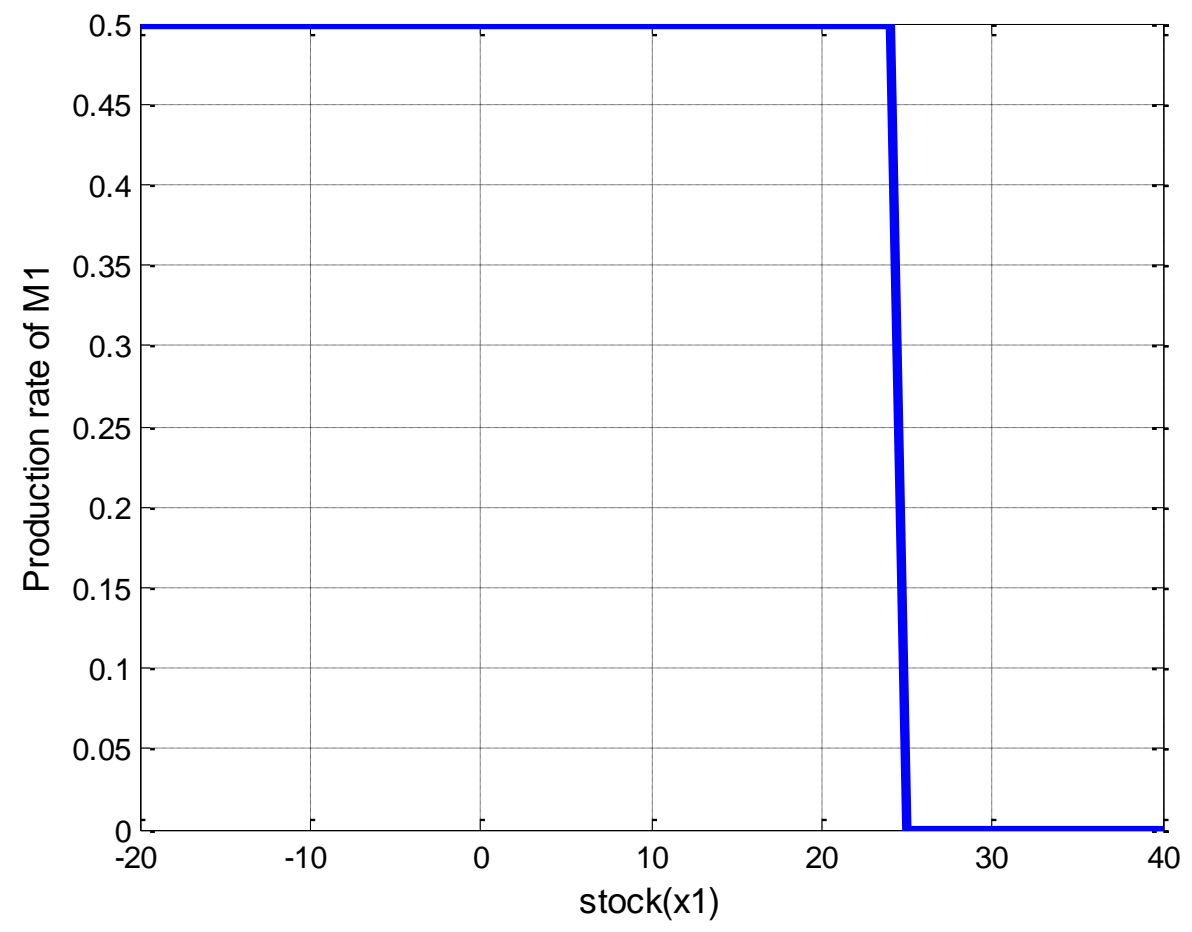

(b)

Figure 4. Production rate of the manufacturing system at mode 1 


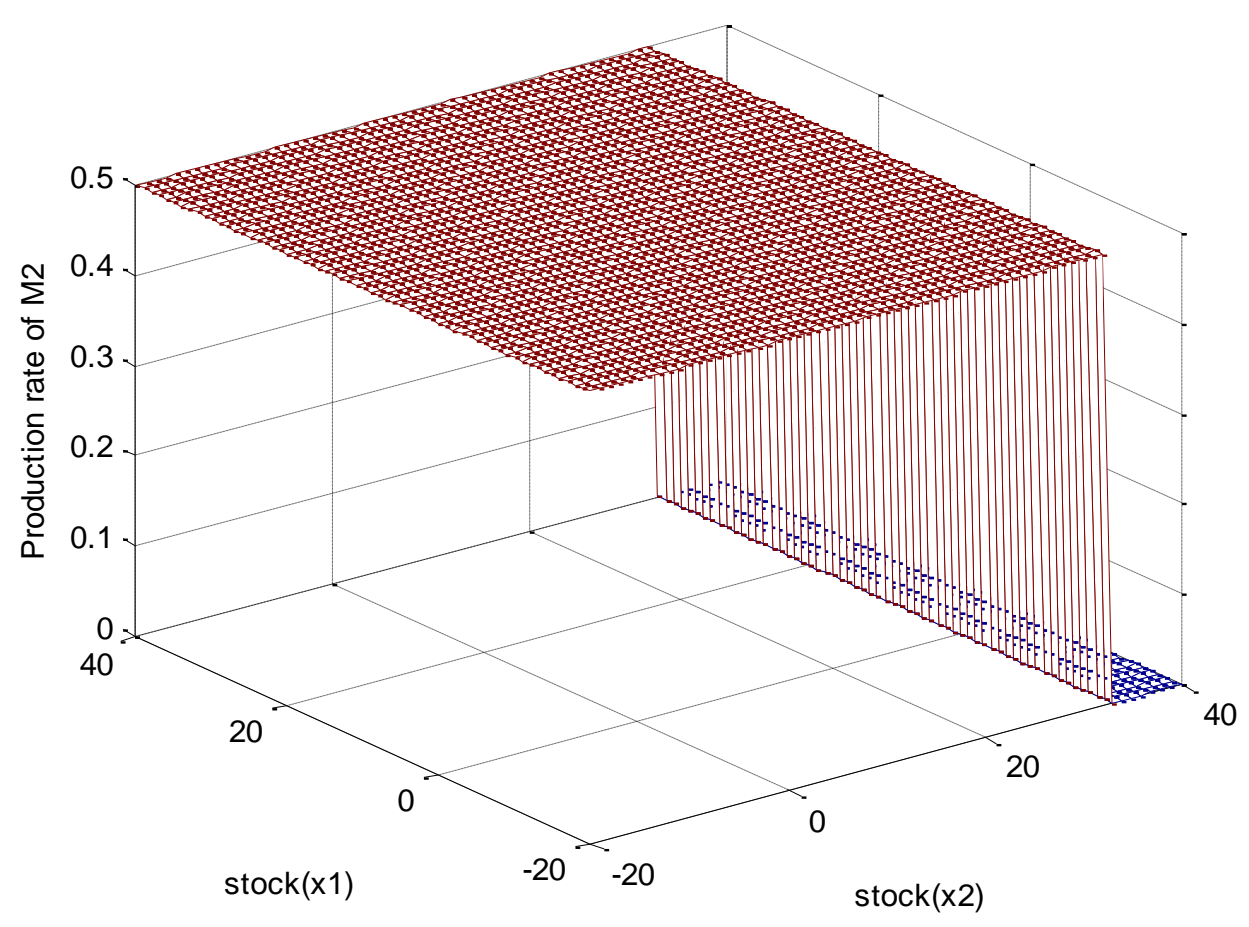

(a)

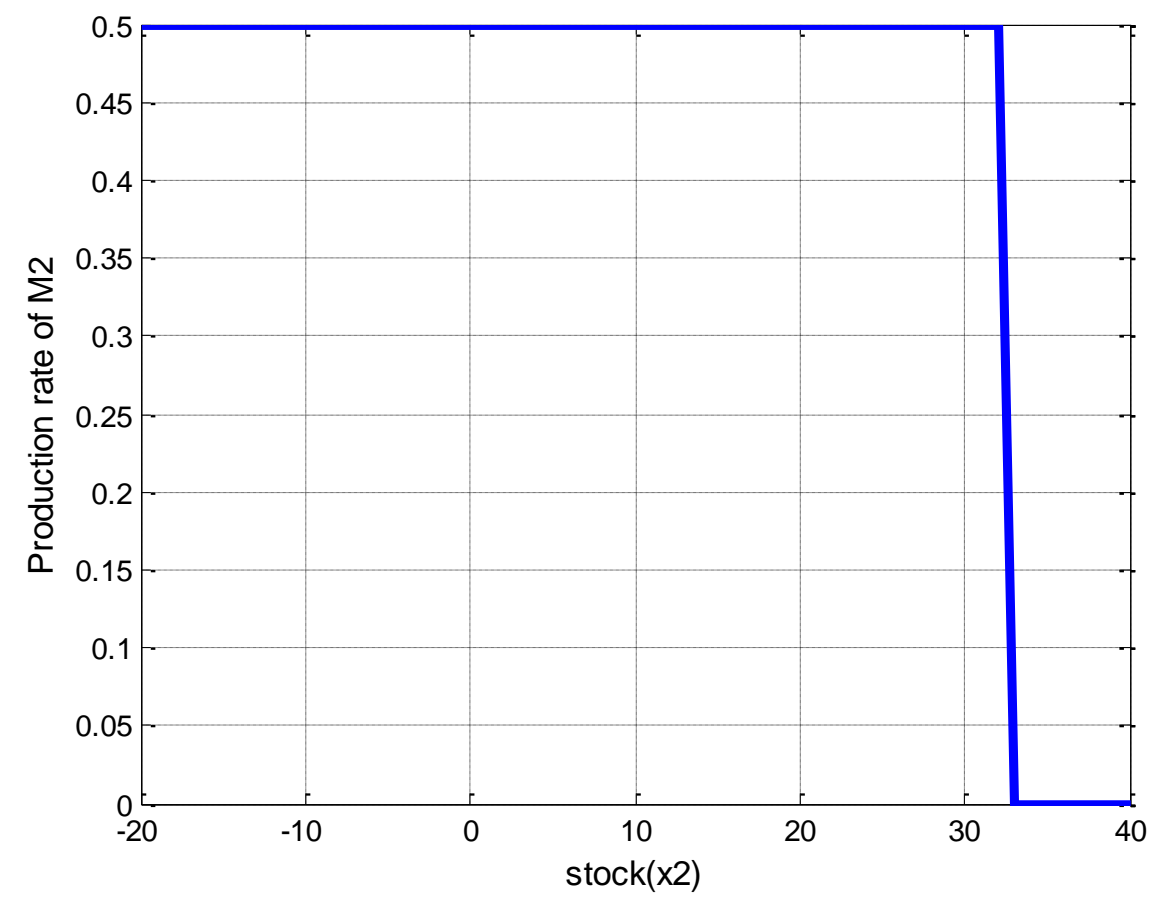

(b)

Figure 5. Production rate of the manufacturing system at mode 1 


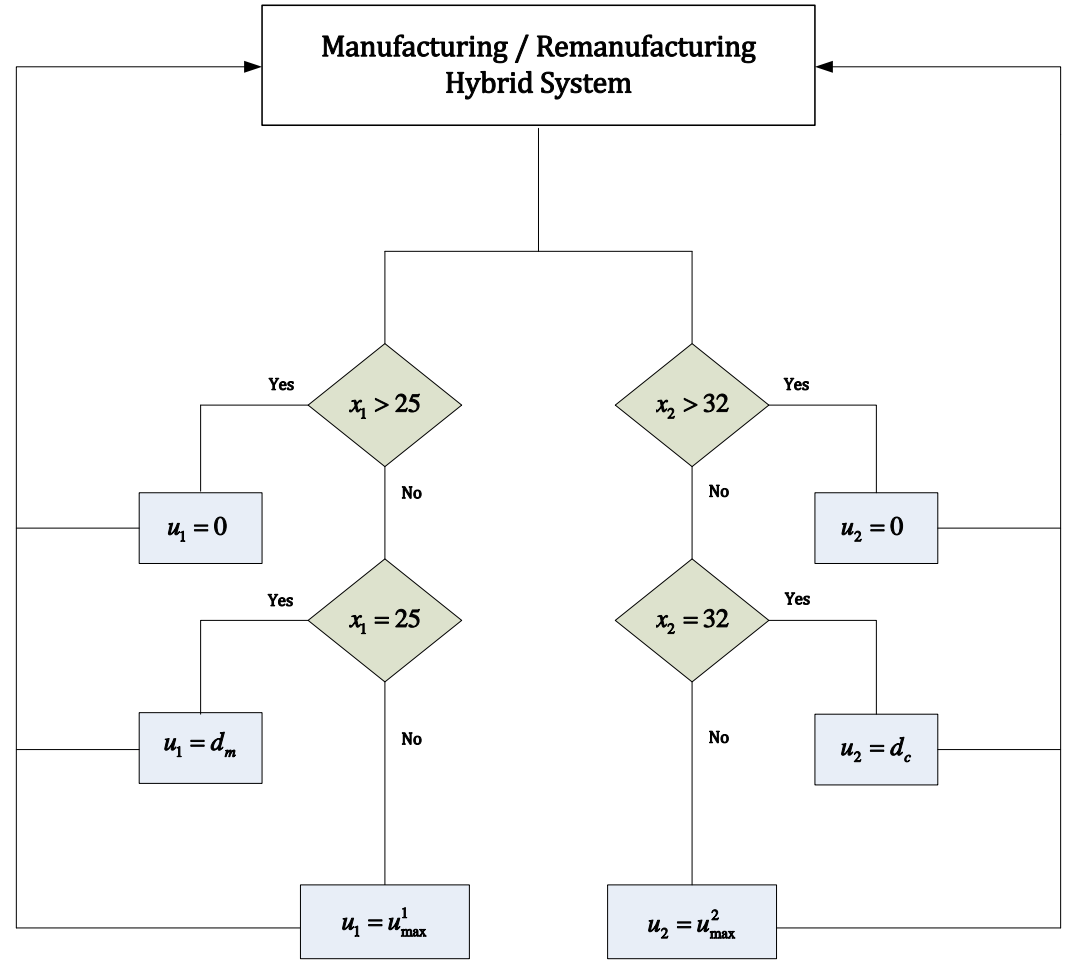

Figure 6. Implementation of the manufacturing/remanufacturing control policy 


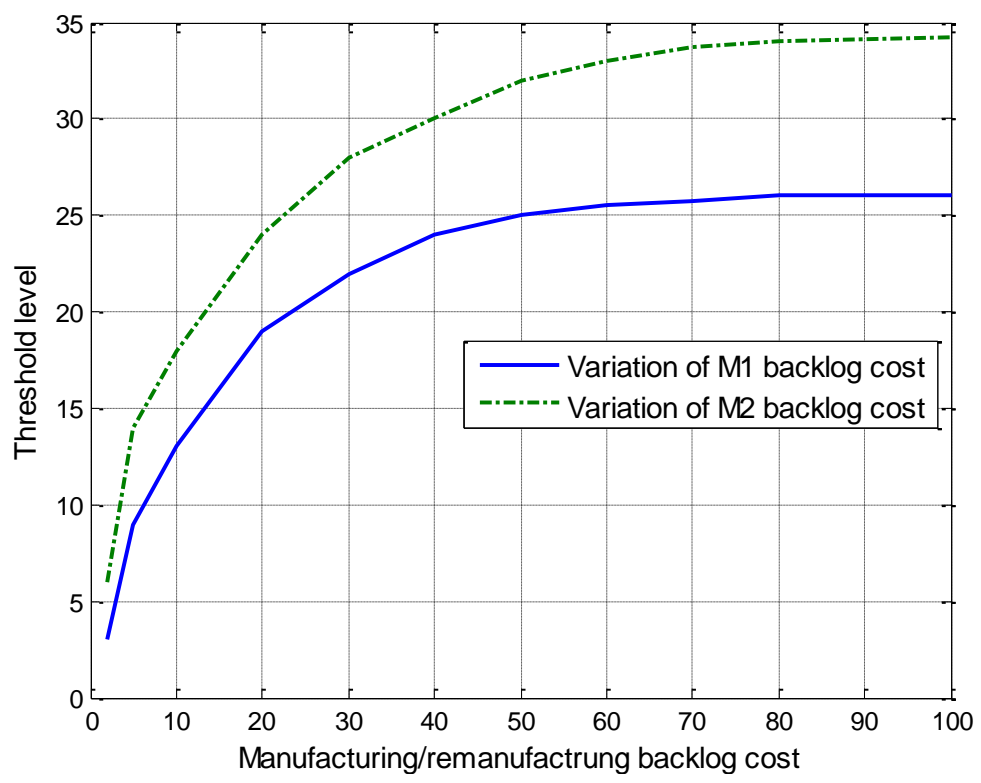

(a)

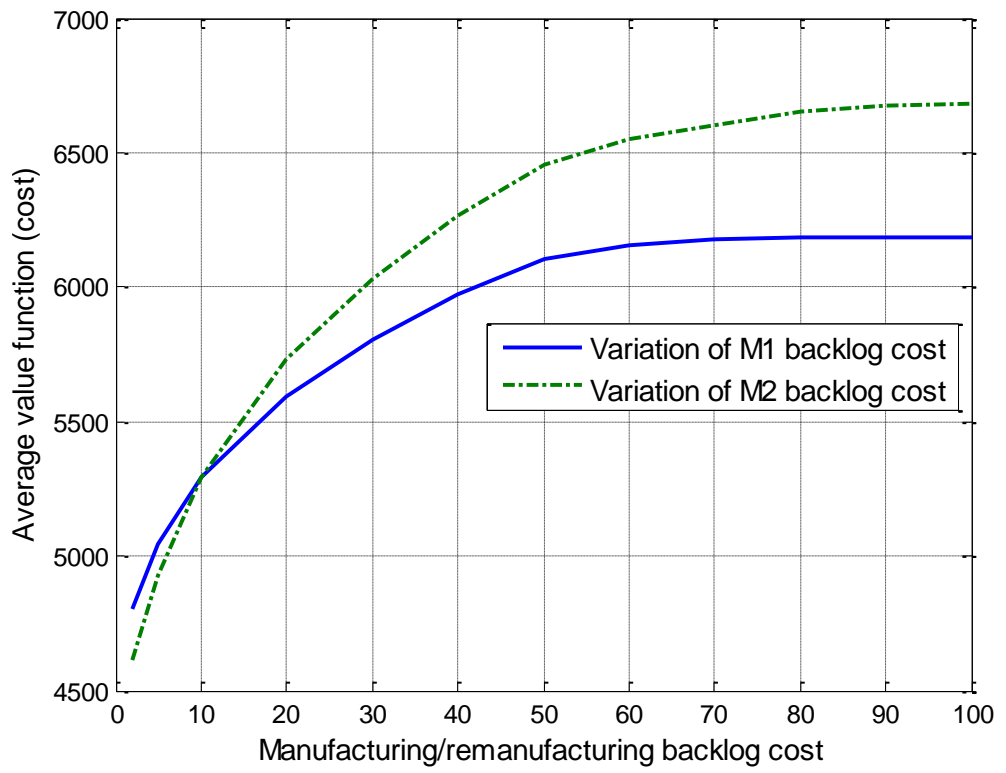

(b)

Figure 7. Threshold levels and average value function for a $50 \%$ return rate 


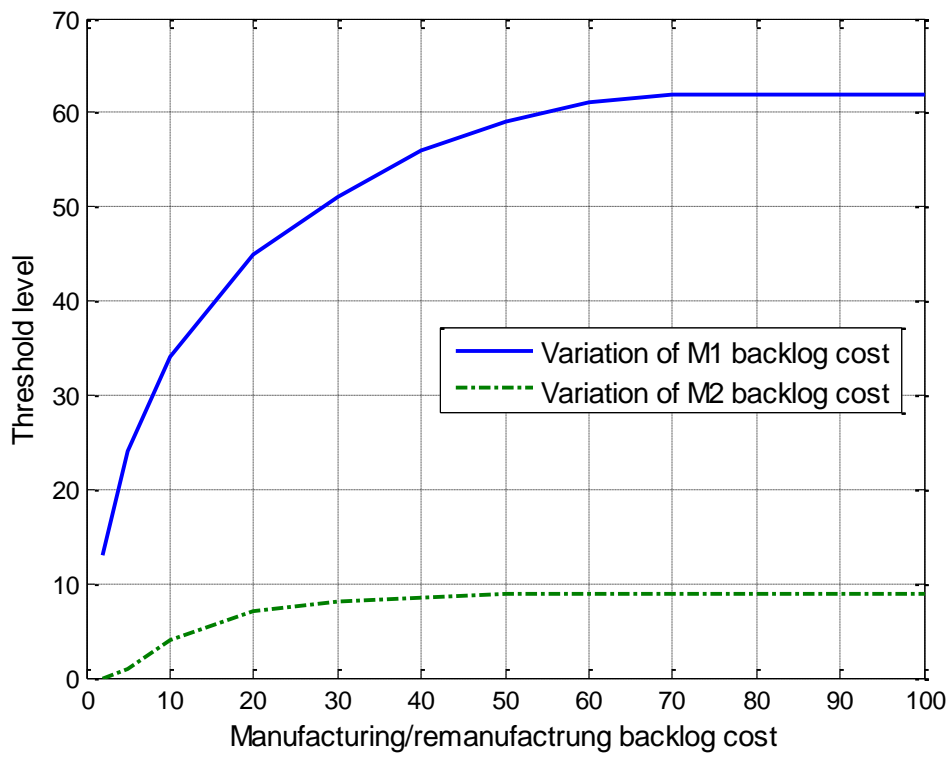

(a)

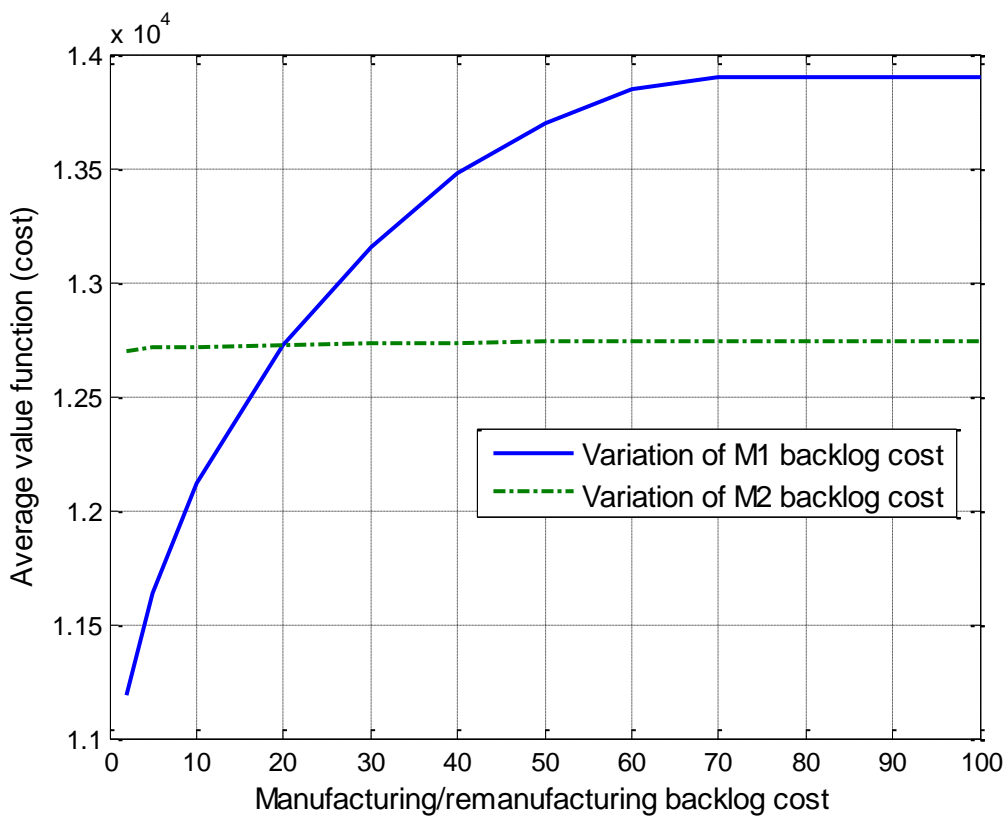

(b)

Figure 8 . Threshold levels and average value function for a $25 \%$ return rate 